\title{
MODERN TECHNOLOGIES IN SPORT, WITH REFERENCE TO VIDEO TECHNOLOGIES
}

\author{
Dejan Vlduka ${ }^{1 *}$, \\ Luka llić ${ }^{1}$, \\ Vanja Dimitrijević ${ }^{2}$
}

\author{
${ }^{1}$ Faculty of Applied Management, \\ Economics and Finance, Belgrade, \\ University of Business Academy, \\ Novi Sad, Serbia \\ ${ }^{2}$ Faculty of Sports and Physical Education, \\ University of Novi Sad, \\ Novi Sad, Serbia
}

\begin{abstract}
:
Modern society is characterized by the global use of advanced technology. One of the spheres of life where technology has great use value is sport. In this paper, we deal with modern technologies that improve sports and results in it. We especially deal with the possibilities of video technology on the sports result itself, the safety of athletes, but also on fairness in decision-making, on economic aspects through the media and the like. The challenges lie in the poor training of users, the lack of creativity to use this technology in a proper way that can achieve better results. Some of the technologies mentioned are video systems in football, water polo and tennis. These are technologies that are now visible and well known to everyone, regardless of whether they believe that this technology has a negative or positive effect on sports. In modern sports, various technologies are implemented that affect the result, whether they are in the form of clothing or protective equipment. These technologies as well as video technology can greatly contribute to improved sports performance in a variety of ways.
\end{abstract}

Keywords:

Video technology, modern sports, modern technologies, influence on sports, digitalization.

\section{INTRODUCTION}

In recent years, there has been a lot of talk about the application of modern technologies in sports as well as in all other activities. In order for the changes in the field of sports to be successful, we must work on the modernization of knowledge and even equipment in sports organizations. Almost all of us know that technology plays a big role in sports, but very few sports workers decide to use that technology in their work. The reason for this phenomenon is usually a lack of knowledge to handle the technique or simply a lack of creativity to improve their work process with technology. The world of sports is constantly changing, and the use of advanced technologies is just one of those areas that have made an impact in many sports activities. [1] As technology enters sports, so do critics, who state that the use of modern technologies will lose the charm of sports competition. 
On the other hand, for many, it makes watching sports more comfortable and fairer in terms of great help to referees in making difficult decisions. For a longer period of time, trainers are able to use video technologies in the training process. [2] With the advent of digital cameras, mobile phones as well as computers, coaches can analyze footage of their athletes and competitors. [3]

Accelerated development and high demand have brought digital video equipment closer to users at lower prices, which was previously a major obstacle in the procurement of such equipment. Until the expansion of the use of video technology in sports, it was not possible without the parallel development and availability of personal computers (PCs) and mobile phones, which are now at a very high level. Sport has increasingly become an interesting economic branch [2] for earnings, and therefore requires a lot of knowledge and resources invested in the development of new content. Videos and TV broadcasts [4] of sporting events are a significant research topic with potentially great commercial value. [5] Demands for efficient acquisition, archiving and postprocessing of competitive sports video sequences are growing. [6] Television production requires new possibilities of monitoring and presentation, adapted to the profile of different viewers. Sports videos are structured as a result of competition rules and regulations. The research goals of computer analysis of sports recordings are efficient indexing and search of video sequences based on queries at a higher semantic level, as well as post-production and 3D graphic reconstruction of a sports event. The aim of this paper is to provide a better insight into what the new technology brings, especially video technology and the way in which it can be used effectively in sports.

\section{LITERATURE REVIEW}

By reviewing the available professional and scientific literature, it is possible to notice a large number of papers that in various ways look at the effects that can be achieved by applying various technologies in sports and thus the specific use of video systems. The works also deal with specific sports through which they analyze the application of video technology. Some of the sports studied are tennis, cricket and bambinton [7], which were among the first to develop a system for monitoring and assisting referees. It is interesting that almost all research is older than ten years, and that the weak representation of this technology in sports is still noticeable. The task of this research is to re-encourage researchers to deal more with this topic and to encourage direct participants to make greater use of available technologies.

\section{MODERN TECHNOLOGY AND ITS IMPACT ON SPORTS}

Modern technology consists of the use of computers and computer networks and modern information methods and techniques. Computer science (computer science and informatics) deals with the study of display and structuring of information, algorithmic processing processes, computer hardware and software. [8] It is experiencing rapid development and has a major impact on all areas of life and work. The media are based on the idea of accepting the means of transmitting information using computers, their digitization, processing and unification. They have become the most successful method of exchanging information among people.

The basic characteristics of information media documents are:

1. digitization of content,

2. computer content processing,

3. archiving in computer memories,

4. transmitting content over a network and

5. displaying content on the screen.

The field of sports is experiencing a very dynamic and intensive development, so the application of information technology is an important factor in its successful functioning. The main factor in the popularization of sports are modern technologies and the opportunities they provide to users. The development of modern technology has resulted in better conditions for both spectators and competitors. Through the development of new technologies, much has been done to improve the results, such as those visible in tennis, athletics and the like. Modern materials are used in the production of synthetic sports surfaces in athletics, so there is a great progress in the 100-meter race compared to the time when these races took place on clay, as well as sports equipment in the form of jerseys and shoes. Sports technologies have evolved for human needs and goals. Technology in sports are also technical means by which athletes try to improve their sports result.

Examples of sports technologies that have improved the sport itself are:

- golf clubs,

- tennis rackets,

- tartan track,

- balls,

- athletic spear,

- mats,

- sports equipment (clothing and footwear) etc.. 
The advantages of advanced technologies in sports are the preservation of health in athletes through heart rate monitoring and similar monitoring of the athlete's health. Through this type of monitoring, medicine itself is advancing, learning about important factors that occur in the human body during extreme loads that the athlete experiences.

Safety at all times is also possible through the development of certain sports equipment, such as helmets used in boxing and ice hockey. Sports equipment, such as a composite tennis racket that provides better control of hitting the ball and achieving greater speed and precision. Prosthetic devices are also designed to help athletes with certain disabilities. Other technologies such as "smart" equipment can be used to evaluate the results achieved, which includes sensors, computers and devices used for exercise, testing human reactions and frequency of movement. More modern technologies such as motion sensors are used to analyze sports results and achievements. This includes digital recording of the athlete's movements during sports activities that can be used to analyze and improve sports results or to educate sports coaches in training techniques and similar requirements.

\section{METHODS AND TECHNIQUES OF APPLICATION OF VIDEO TECHNIQUE IN SPORTS}

One of the basic applications of video analysis is the development of sports team tactics in the process of training or preparation for a match. [2] Methods for classifying video sequences into tactical templates are being investigated. The analysis of tennis game tactics is based on the classification of sequences based on the identification of the player's movements and the trajectory of the tennis ball. Performance analysis of a team or player is based on analysis of movement and activity in the game. Coaches and players are interested in the results of the analysis, with the aim of improving the team's performance in future competitions. The basic techniques of analysis are detection and tracking of players and balls, behavioral analysis and active play. Methods of tracking players, balls and referees are the basis for further analysis. The basic technique is to evaluate the images of networked cameras that cover the sports field. Synchronized cameras follow the complete trajectory of the ball. These images are processed in a computer 3D system (HawkEye) [9] and the position of contact of the ball with the substrate and the bounce are generated.
Also known is the VAR (Video Assistant Referee) system used in football where it monitors aspects of the game that are in line with the propositions of the football game. A similar system is used in water polo called VMS (Video Monitoring System). As in swimming, where, as in athletics, he looks at the photo finish in sprint disciplines.

First, we need to describe the video technology commonly used in coaching. A simple mobile phone with a camera, which has become the standard for most people over the years. The phone can be combined with a laptop for feedback and qualitative analysis. [3] The goal and purpose of using video technology is to improve the field process and increase the performance of the athlete. [10] This technology also facilitates learning in the training process where it contributes to a better understanding of all aspects of the training process. [11] In addition to the training process, this equipment can be used in training in educational institutions, in preparing tactics by analyzing videos of opponents or by analyzing your videos in order to eliminate mistakes.

Video training technology, several video cameras and taking shots from all sides, a coach can have several different views on sports performance. By slowing down the recording, the coach can see the performance of his athlete and the mistakes he may make. [12] Sometimes, athletes who make small changes in technique feel that they have made a big change, but the coach sees well those changes that he can analyze with his athlete in order to achieve even better results. Another advantage is the placement of the camera in areas where the coach cannot go, and in this way monitor the work of both his athletes and competitors. In field sports a camera set high in the stands provides a field of view for the coach that is limited from the bench to the field, this is especially evident in football. [13]

\section{THE FUTURE}

The development of ultra-fast digital camera techniques and video processing methods has initiated research in all sports: recording and playback of networked cameras, player and ball tracking, video analysis and production of key event reviews. [3] Methods of tracking players, balls and referees form the basis for further analysis. In tennis [14], images are processed in a computer 3D system (HawkEye) and the position of contact of the ball with the surface and the bounce are generated. 
This automated computer system called HawkEye for displaying the position of field boundary lines and automatically checking the correctness (IN / OUT) of the referee's decision. [9]

Using the Python programming language, it is possible to create a small program that can identify objects in the field and, based on the given parameters, signal some of the errors, such as offside or out. Such programs are taught to be made by undergraduate students and are therefore not very complicated, and can be adapted to various purposes that allow the video technique to be used in the best possible way.

This type of application of technology requires the involvement of several experts. In addition to the trainer, scientists who deal with analysis and a programmer who can enable the effective use of the technique should be involved. As in all other segments of life, the challenge is to synchronize these three seemingly difficultto-connect professionals. Access to the maximum use of technology is possible only if the problem is viewed multidisciplinary, this is visible today in other segments such as medicine and similar sciences. One of the visible challenges is the poor training of trainers, who in a large number of cases are not trained at their faculties to use modern technology, and therefore use it in small numbers. [3] This is a very important segment of progress and application of modern means and should be given special attention, and faculties should pay more attention to these technologies so that students come out with rich knowledge of the use and application of modern technology.

\section{CONCLUSION}

The successful functioning of sports organizations and its employees depends on many factors, and one of them is the application of modern technologies that facilitate and improve sports results. In many organizations, the application of modern technologies in the form of information technologies is very poorly represented. A partial reason for that is poor training, but also a low threshold of creativity that would help in that intention. One of the technologies that stands out, and is accessible to everyone in some way, is video technology. This technology, among all others, has a very big impact on sports, but it is poorly used or misused by our experts, scientists and athletes themselves. This problem should be viewed multidisciplinary through, sports, technology, psychology, creativity, etc. The only way to progress in sports as well as in other activities is to join teams of professional and creative people with the goal of progress. Faculties that educate sports experts to apply technologies are in charge of creating the knowledge that is needed. But also the obligation of all other faculties to educate people to connect and to develop their reactivity that can enable them unprecedented progress.

\section{REFERENCES}

[1] R. Leveaux, „Facilitating Referee's Decision Making in Sport via the Application of Technology", IBIMA Publishing, Communications of the IBIMA, Vol. 2010, Article ID 545333, 8 pages, 2010, Doi: $10.5171 / 2010.545333$

[2] J. R. Wang and N. Parameswaran, „Survey of Sports Video Analysis: Research Issues and Applications", Conference: Visual Information Processing 2003, Proceedings of the Pan-Sydney Area Workshop on Visual Information Processing, VIP, 2003.

[3] M. Ivanović and U. Ivanović, ,Savremene informacione tehnologije u nastavi fizičkog vaspitanja”, Technics and Informatics in Education, 4 th International Conference, Technical Faculty Čačak, Serbia, 1-3rd June 2012.

[4] A. Hanjalic, „Adaptive Extraction of Highlights From a Sport Video Based on Excitement Modeling", IEEE Transactions on Multimedia, Vol. 7, No. 6, 2005.

[5] A. Hanjalic, „Generic Approach to Highlights Extraction From a Sport Video", Delft University of Technology, Delft, The Netherlands, 2003.

[6] D. Milanović, I. Jukić and S. Šimek, „Informatizacija u području sporta", 14. Ljetnja škola kinezilogije Republike Hratske, 2005.

[7] M. V. Huynh and A. Bedford, „Evaluating a computer based skills acquisition trainer to classify badminton players", Journal of Sports Science and Medicine (2011) 10, 528-533.

[8] M. Varga, „Informacijski sustav u poslovanju.” Informacijska tehnologija u poslovanju. Element, Zagreb, 2004.

[9] H. Collins and R. Evans, „You cannot be serious! Public understanding of technology with special reference to Hawk-Eye", SAGE Publications, Public Understand. Sci. 17 (2008) 283-308.

[10] A. G. Liebermann, La. Katz, M. D. Hughes, R. M. Bartlett, J. McClements and I. M. Franks, „Advances in the application of information technology to sport performance", Journal of Sports Sciences, 2002, 20, $755-769$.

[11] M. J. Barwood, N. J. V. Weston, R. Thelwell and J. Page, „A motivational music and video intervention improves high-intensity exercise performance", Journal of Sports Science and Medicine (2009) 8, 435-442. 
[12] B. D. Wilson, „Development in video technology for coachingy", Sports Technol. 2008, 1, No. 1, 34-40.

[13] F. Chen and C. D. Vleeschouwer, „Formulating Team-Sport Video Summarization as a Resource Allocation Problem", IEEE Trans. on Circuits and Systems for Video Tech., Vol. XX, No. 1, 2011.

[14] J.H. Lai and S.Y. Chien, „Tennis Video 2.0 : A New Framework of Sport Video Applications", Media IC and System Lab, Graduate Institute of Electronics Engineering and Department of Electrical Engineering, National Taiwan University, 2003. 